\title{
Dissecting cholesterol and phytosterol biosynthesis via mutants and inhibitors
}

Kjell De Vriese ${ }^{1,2}$, Jacob Pollier ${ }^{1,2,3}$, Alain Goossens ${ }^{1,2}$, Tom Beeckman ${ }^{1,2}$, Steffen Vanneste $e^{1,2,4, *}$

1: Department of Plant Biotechnology and Bioinformatics, Ghent University, Technologiepark 71, 9052 Ghent, Belgium

2: VIB Center for Plant Systems Biology, VIB, Technologiepark 71, 9052 Ghent, Belgium

3: VIB Metabolomics Core, Technologiepark 71, 9052 Ghent, Belgium

4: Lab of Plant Growth Analysis, Ghent University Global Campus, Songdomunhwa-Ro, 119, Yeonsu-gu, Incheon 21985, Republic of Korea

e-mails:

K.D.V: kjvri@psb.vib-ugent.be

J.P: japol@psb.vib-ugent.be

A.G. algoo@psb.vib-ugent.be

T.B. tobee@psb.vib-ugent.be

S.V. steffen.vanneste@ugent.be

${ }^{*}$ Corresponding author

Tel: +3293313844

Kjell De Vriese, Jacob Pollier, Alain Goossens, Tom Beeckman, Steffen Vanneste

(C) The Author(s) 2020. Published by Oxford University Press on behalf of the Society for Experimental Biology. All rights reserved. For permissions, please email:

journals.permissions@oup.com 


\section{ABSTRACT}

Plants stand out among eukaryotes by the large variety of sterols and sterol derivatives that they can produce. These metabolites not only serve as critical determinants of membrane structures, but also act as signaling molecules, as growth regulating hormones, or as modulators of enzymatic activities. Therefore, it is critical to understand the wiring of the biosynthetic pathways by which plants generate these distinct sterols, to allow manipulating them and dissect their precise physiological roles. Here, we review the complexity and variation of the biosynthetic routes of the most abundant phytosterols and cholesterol in the green lineage and how different enzymes in these pathways are conserved and diverged from humans, yeast and even bacteria. Many enzymatic steps show a deep evolutionary conservation, while others are executed by completely different enzymes. This has important implications for the use and specificity of available human and yeast sterol biosynthesis inhibitors in plants, and argues for the development of plant-tailored inhibitors of sterol biosynthesis. 
Highlight statement:

The complexity and diversification of sterol biosynthesis in the green lineage make it difficult to manipulate plant sterol biosynthesis via currently available small molecule inhibitors. 


\section{Introduction}

Sterols are a class of triterpenoid lipids that consist of a hydrated phenanthrene group and a cyclopentane ring. These molecules have a crucial impact on membrane fluidity and transmembrane export and import processes, and some sterols can even act as second messengers or signaling molecules during developmental and cellular signaling processes (Boutté and Grebe, 2009; Boutté and Jaillais, 2020; Valitova et al., 2016; Vriet et al., 2013).

The ancient rise in atmospheric $\mathrm{O}_{2}$ levels enabled the evolution of the oxygendependent sterol biosynthesis pathways found in all eukaryotes (Galea and Brown, 2009; Mouritsen, 2005), and is often used as an indicator of eukaryotic life. This is contrasted by the occurrence of hopanoids in prokaryotes, which are ring-structured molecules that look similar to sterols and exert analogous functions in the membranes as cholesterol, but do not require $\mathrm{O}_{2}$ for their biosynthesis and lack a 3ß-hydroxyl group (Saenz et al., 2015). Notably, some bacteria also produce sterols, a feature that was presumably gained via horizontal gene transfer (Bode et al., 2003; Rivas-Marin et al., 2019).

While sterols occur in all eukaryotic organisms, the types and amounts of the main sterols vary considerably between the different kingdoms. In example, the major sterol produced in animals is cholesterol, whereas fungi mainly produce ergosterol. Plants, on the other hand, produce a wide variety of sterols (or phytosterols), with over 200 variants known to date (Benveniste, 2004; Guo et al., 1995; Schaller, 2004). Among the phytosterols, campesterol, stigmasterol and $\beta$-sitosterol make up the predominant molecules of the sterol profile in plants (Benveniste, 2004; Schaeffer et al., 2001). Cholesterol and derivatives are typically 100- to 1000-fold less abundant in plants than in humans, but in some species they make up a large fraction of the total sterol content, as seen in canola, Solanaceae, Liliaceae and Scrophulariaceae (Behrman and Gopalan, 2005). In addition to free sterols, plants also accumulate a variety of sterol conjugates such as fatty acid acyl sterol esters (SE), steryl glucosides (SG) and acyl steryl glucosides (ASG) (Ferrer et al., 2017; Zhang et al., 2020). A survey of different diatoms also revealed a very complex sterol landscape, again with a completely different set of specific sterols being the most abundant, even varying between different diatom lineages (Rampen et al., 2010). Also the green algae display a markedly distinct sterol profile compared to land plants, being mainly dominated by cholesterol, 24methylene cholesterol and 28-isofucosterol (Li et al., 2017; Lopes et al., 2011). This diversity in sterol composition is sufficient to allow for chemotaxonomic classification of algae (Taipale et al., 2016).

The common evolutionary origin makes that many conserved enzymatic activities of sterol biosynthesis across the eukaryotic kingdoms are sensitive to the same pharmacology. 
This allows to use a part of the vast sterol pharmacology, which was originally designed to inhibit human or fungal sterol biosynthesis, to interfere with corresponding enzymes in plants. Here, we review our current understanding of phytosterol and cholesterol biosynthesis in plants, and highlight available pharmacology and mutants, mainly using Arabidopsis (Arabidopsis thaliana) as an example.

\section{Early sterol biosynthesis - building the universal terpene precursors}

Squalene is the universal precursor of triterpenes; in prokaryotes for hopanoids and in eukaryotes of steroids (including phytosterols, lanosterol and cholesterol). For details about its biochemistry, we refer the reader to specialized literature (Henry et al., 2018; Vranova et al., 2013). In brief, squalene is formed by the condensation of two farnesyl pyrophosphate (FPP) units by SQUALENE SYNTHASE (SQS), and FPP is an assembly of two IsoPentenyl Pyrophosphates (IPP) and one molecule DiMethylAllyl PyroPhosphate (DMAPP), catalyzed by FPP SYNTHASE (FPPS) (Fig. 1). The cytoplasmic IPP and DMAPP levels are subject to a highly complex metabolic regulation in plants, possibly involving at least two distinct mechanisms. The best characterized, and most important pathway for cytosolic IPP production is the mevalonate (MVA) pathway, which is largely conserved across eukaryotes and archaea. Central to this pathway is the activity of 3-hydroxy-3-methylglutaryl-CoA reductase (HMGR) that produces MVA a precursor of IPP and DMAPP (Fig. 1). An alternative MVA pathway generates isopentenyl phosphate (IP) and dimethylallyl phosphate (DMAP), which can be phosphorylated to form IPP and DMAPP (Henry et al., 2015; Henry et al., 2018). The methylerythritol phosphate (MEP) pathway produces IPP and DMAPP in plastids (Banerjee and Sharkey, 2014), of which a fraction feeds into the cytoplasm (Kasahara et al., 2002). The contribution of the MEP pathway to the cytoplasmic IPP pool varies greatly between species, which in some green algae led to the complete loss of the MVA pathway (Lohr et al., 2012).

Despite the complex regulation of cytoplasmic IPP and DMAPP levels, HMGR activity has been shown to be rate-limiting for sterol biosynthesis in plants (Shimada et al., 2019). Also in humans, HMGR activity is rate-limiting for cholesterol biosynthesis making it a major therapeutic target for treating hypercholesterolaemia (Davies et al., 2016). This medicinal application has led to the development of statins that compete with the endogenous substrate for the HMG-CoA-binding site in HMGR (Istvan and Deisenhofer, 2001). Given the deep evolutionary functional conservation of HMGR activity, statins, such as lovastatin and mevastatin, are also potent inhibitors of plant HMGRs. Consistently, the Arabidopsis $h m g r$ mutants ( $h m g 1$ and $h m g 2$ ) are hypersensitive to lovastatin (Suzuki et al., 2004). Moreover, lovastatin treatment had a fast, but transient, negative effect on sterol 
content in Arabidopsis seedlings, suggesting compensatory IPP and DMAPP flux from the plastids into the cytosol (Laule et al., 2003).

The subsequent assembly of IPP and DMAPP into FPP can be impaired by inducible gene silencing of both Arabidopsis FPSs resulting in a reduction of sterol levels, but also defects in plastidial terpene metabolism (Manzano et al., 2016). The complete loss of FPS function was embryonic lethal (Closa et al., 2010). While human FPS can be potently inhibited by nitrogen-containing bisphosphonates (Drake et al., 2008), these inhibitors are currently not commonly used in plants.

The subsequent condensation of FPP into squalene depends on a single functional SQS in Arabidopsis (SQS1; (Busquets et al., 2008). This SQS can complement a $S$. cerevisiae erg9 null mutant and displayed the expected biochemical activity in vitro (Busquets et al., 2008; Kribii et al., 1997). No mutants have been characterized to date. Squalestatins (also called zaragozic acids), are highly potent and specific competitive inhibitors of rat SQS, with apparent subnanomolar Ki values (Baxter et al., 1992; Bergstrom et al., 1993). Also in plants, squalestatins are highly potent inhibitors that inhibit SQS in BY-2 cell suspensions with an $\mathrm{IC}_{50}$ value of $5.5 \mathrm{nM}$, possibly via an irreversible inhibition mechanism (Hartmann et al., 2000; Wentzinger et al., 2002). Interestingly, exogenous application of squalestatins to Arabidopsis plants impairs the plants' fertility and induces transcriptional responses that are also induced in lovastatin-treated plants (Suzuki et al., 2004). The transcriptional changes seen after squalestatin or lovastatin treatment were proposed to reflect a response to defective isoprenoid or non-brassinosteroidal steroid accumulations, via an unknown mechanism rather than an effect of reduced cytokinin biosynthesis (Suzuki et al., 2004). One possible explanation is that sterol deficiency differentially regulates the activities of homeodomain containing transcription factors that contain a lipid/sterol binding StAR-related lipid transfer (START) domain (Schrick et al., 2014; Schrick et al., 2004). An interesting consequence of inhibiting SQS by squalestatin is the increased availability of FPP for sesquiterpene biosynthesis (Kobayashi et al., 2017).

\section{Committing to sterol biosynthesis - Squalene Epoxidase}

The subsequent, oxygen-dependent epoxidation of squalene into 2,3-oxidosqualene by SQUALENE EPOXIDASEs (SQEs), is a key step in eukaryotic sterol biosynthesis (Thimmappa et al., 2014). Of three functional SQEs in Arabidopsis that can rescue SQEdeficient yeast (Laranjeira et al., 2015; Rasbery et al., 2007), only SQE1 seems to play the most predominant function, as a single sqe1 mutant already displays pleiotropic phenotypes in the root and shoot (Posé et al., 2009; Rasbery et al., 2007). However, these phenotypes 
were not due to the reduced sterol content of the mutant, but because of hyperaccumulation of its substrate, squalene (Doblas et al., 2013).

Docking analyses on modelled SQE suggest that the allylamine fungicide, terbinafine, causes a conformational change that blocks one mode of substrate binding, while changing the geometry of another (Nowosielski et al., 2011). Although conventional plant SQEs can complement yeast SQE deficient mutants (Rasbery et al., 2007), they are not highly sensitive to these inhibitors (Wentzinger et al., 2002). This is not surprising as single amino acid substitutions in SQE are sufficient to confer terbinafine resistance to yeast mutants (Leber et al., 2003). Yet, the sqe1-5 mutant is hypersensitive to terbinafine (Posé et al., 2009). On the other hand, some organisms, such as the diatom $P$. tricornutum, are completely insensitive to terbinafine (Fabris et al., 2014; Pollier et al., 2019). This can be easily explained by the presence of an alternative SQE, that belongs to the fatty acid hydroxylase superfamily, instead of to the common flavoprotein monooxygenase-type SQEs (Pollier et al., 2019), thus requiring a specific pharmacology.

\section{Committing to sterol biosynthesis - Oxidosqualene Cyclases}

The biosynthetic step that forms the branch point between primary sterol biosynthesis and specialized triterpene metabolism is the cyclization of oxidosqualene catalyzed by specialized oxidosqualene cyclases (OSCs) (Fig. 2). These OSCs evolved from bacterial squalene/hopane synthases, and the Arabidopsis genome contains 13 of them. In contrast to animals and yeast that use lanosterol as the first cyclic intermediate in cholesterol and ergosterol biosynthesis, respectively, plants use cycloartenol as the main cyclic intermediate in phytosterol and cholesterol biosynthesis (Fig. 2). This 2,3-oxidosqualene cyclization product is produced by the enzyme cycloartenol synthase 1 (CAS1) in Arabidopsis (GasPascual et al., 2014; Thimmappa et al., 2014). In addition to CAS, Arabidopsis also encodes lanosterol synthase (LAS), lupeol synthase (LUP1), and $\beta$-amyrin synthase (bAS), OSCs that show a widespread occurrence throughout the plant kingdom (Miettinen et al., 2018; Thimmappa et al., 2014) with a suggested role in phytosterol biosynthesis (LAS) or plant defense (LUP1, bAS). In addition to these "universal" plant OSCs, Arabidopsis also encodes a set of OSCs that are specific to Brassicaceae or even to Arabidopsis as a species. These OSCs include thalianol synthase (THAS), marneral synthase (MRN1) and arabidiol synthase (PEN1), OSCs with a suggested role in plant defense and modulation of the root microbiome (Huang et al., 2019).

While strong cas 1 mutant alleles are male gametophytic lethal, hypomorphic cas 1-1 mutants displayed organ-specific albinism (Babiychuk et al., 2008). Strikingly, although these hypomorphic mutants accumulate 2,3-oxidosqualene, the total phytosterol levels, albeit with 
a reduction in $\beta$-sitosterol, remained unchanged in cas 1-1 mutants, suggesting the existence of alternative pathways contributing to phytosterol biosynthesis (Babiychuk et al., 2008). With exception of a significant reduction in $\beta$-sitosterol content, similar results were obtained by overexpression of CYTOKININ-INDUCED F-BOX (CFB) that stimulates CAS1 turnover (Brenner et al., 2017). Interestingly, cas1-1 also had reduced cholesterol levels (Babiychuk et al., 2008), consistent with the recent identification of cycloartenol as a precursor in cholesterol biosynthesis in plants (Fig. 3) (Sonawane et al., 2016).

A possible alternative route for phytosterol biosynthesis is LAS-dependent (Fig. 2). The Arabidopsis genome encodes for one functional LAS gene that can complement a lanosterol synthase deficient yeast strain (Kolesnikova et al., 2006; Sawai et al., 2006; Suzuki et al., 2006). However, the las 1 knock-out, besides a reduction in sitostanol, did not display gross changes in total endogenous sterol content (Suzuki et al., 2006). Tracer feeding confirmed that the LAS pathway accounts for $+/-1.5 \%$ of $\beta$-sitosterol biosynthesis in Arabidopsis, which could be increased to $4.5 \%$ by overexpression of LAS1 (Ohyama et al., 2009). How lanosterol is converted into phytosterols remains currently unknown.

In humans, the benchmark OSC inhibitor is the competitive inhibitor RO 48-8071 (Thoma et al., 2004). Similar to cas1-1 mutants, this inhibitor causes the accumulation of 2,3-oxidosqualene in Arabidopsis seedlings and in plant cell suspensions (Gas-Pascual et al., 2015). Only after prolonged treatments (6 days), it also caused reductions of $\beta$-sitosterol and stigmasterol, and an increase of campesterol, that was probably due to a transcriptional downregulation of SMT2 (see further) (Gas-Pascual et al., 2015). The stronger effect on phytosterol content by the inhibitor treatment than in the cas 1 mutant might be explained by additional inhibition of other OSCs that contribute to phytosterol biosynthesis, such as LAS1. Recently, LauryIDiMethylAmine Oxide (LDAO) was characterized as potent CAS1 inhibitor in Arabidopsis, but also the more downstream CPI activity (Darnet et al., 2020).

\section{Diversification of the sterol end-products - side chain metabolism}

Cycloartenol is a precursor for the biosynthesis of phytosterols as well as of cholesterol in plants, respectively by methylation at the C24-position by the C-24 sterol methyltransferase SMT1, or by $\Delta 24$ reduction via STEROL SIDE CHAIN REDUCTASE 2 (SSR2) (Fig. 3) (Sawai et al., 2014; Sonawane et al., 2016).

In Arabidopsis, SMT1 catalyzes the formation of $\Delta^{5} \mathrm{C}-24$ alkyl sterols that are precursors for campesterol, $\beta$-sitosterol and stigmasterol. Its enzymatic activity was demonstrated via biochemical assays and via an ERG6-deficient yeast complementation assay (Diener et al., 
2000). At the level of the sterol content, smt1 mutants showed a reduction in $\beta$-sitosterol, but not in campesterol content (Diener et al., 2000; Schrick et al., 2002; Willemsen et al., 2003). The normal campesterol levels are surprising as campesterol should derive from the same SMT1-dependent pathway as $\beta$-sitosterol. One explanation could be that the diverged SMT2 and SMT3 can partially substitute for the lack of SMT1 at the expense of their normal, more downstream function in producing ethylsterols, such as $\beta$-sitosterol, resulting in a higher flux of precursors into campesterol biosynthesis.

Later in the pathway, from 24-methylenelophenol onwards, the pathway bifurcates via two separate branches, to form the 24-ethylsterols, $\beta$-sitosterol and stigmasterol, or the 24-methylsterol, campesterol, as end-products, respectively (Fig. 3,4). The bifurcation is due to the formation of an ethyl side-chain at the C-24 position, via a second type of SMTs (in Arabidopsis, SMT2/COTYLEDON VASCULAR PATTERN 1 (SMT2/CVP1) and SMT3) (Carland et al., 2010; Schaeffer et al., 2001). Therefore, the activity of these SMT enzymes controls the balance of ethylsterol and methylsterols. Consistently with the proposed position of SMT2/3 in the pathway, the cvp1 single and cvp1smt3 double mutants accumulate 24-methylenelophenol, and campesterol biosynthesis at the expense of stigmasterol and $\beta$-sitosterol. Intriguingly, the sterol profile of the cvp1smt3 double mutant showed marked resemblances to that of smt1, such as increased cholesterol and 24methylenecholesterol levels, suggesting partially overlapping biochemical functions at the first methylation step (Carland et al., 2010).

In contrast to mammals that synthesize cholesterol via a lanosterol intermediate, plants mainly initiate cholesterol biosynthesis using cycloartenol as a precursor (Sawai et al., 2014; Sonawane et al., 2016). The responsible gene was identified in a homology blast using the human DHCR24 amino acid sequence as a query (Sawai et al., 2014). While two homologs with different specificities were identified in potato and tomato, SSR1 and SSR2, Arabidopsis contains only SSR1, previously identified as DWF1, an enzyme that was characterized in a more downstream step of phytosterol biosynthesis. Gene-silencing of SSR2 in potato caused a reduction in cholesterol, and cholesterol-derived steroidal glycoalkaloids, and an increase in campesterol and $\beta$-sitosterol levels (Sawai et al., 2014). Conversely, cholesterol became the most abundant sterol in the Arabidopsis smt1 alleles (Diener et al., 2000; Schrick et al., 2002; Willemsen et al., 2003), a phenomenon that is also observed in a bermudagrass mutant with reduced SMT1 expression (Chen et al., 2018). The increase in cholesterol levels is consistent with SMT1 competing with SSR2 for the precursor cycloartenol. Notably, Arabidopsis contains no known SSR2 enzyme that could explain the cholesterol accumulation in smt1 mutants, suggesting that its SSR1 displays some SSR2 activity. 
Several side-chain azasterols, carbocationic transition state analogues of the substrates of SMT, were previously identified as SMT inhibitors in yeast (Renard et al., 2009). Feeding experiments allowed for the identification of several azasterols that selectively inhibit either SMT1 or SMT2/SMT3 activities (Darnet et al., 2020). The SMT1selective azasterols caused sterol profiles typically observed in smt1 mutants, including accumulation of cholesterol and cycloartenol. The homology of SSR to human DHCR24 suggests that DHCR24 inhibitors could be used as templates to develop selective SSR1 and SSR2 inhibitors, similarly as was done for SMT1 and SMT2/3.

\section{A double C4-demethylation via distinct sets of Sterol-4a-Methyl Oxidases}

While in mammals and yeast a double demethylation at the $\mathrm{C} 4$ position is executed consecutively by a single multi-enzyme complex, plants have up to four distinct C4demethylation complexes, acting at different positions in the pathway (Fig. 3) (Darnet and Schaller, 2019). The highly conserved C4-demethylation complex (C4-DMC) consists of sterol-4a-methyl oxidase (SMO), 4a-carboxysterol-C3-dehydrogenase/C4-decarboxylase (CSD) and sterone ketoreductase (SR), tethered together via ERG28 (Mialoundama et al., 2013; Sonawane et al., 2016).

Plant SMOs can largely complement the 4,4-dimethyl sterol accumulation in the erg25 mutant yeast strains (Darnet et al., 2001). The first family, SMO1, is specifically involved removal of a single methyl group from the C-4 position of the 4,4-dimethyl sterol, 24-methylenecycloartenol, generating the 4-methyl sterol, cycloeucalenol. The second family (SMO2) is specifically active in removing the second methyl at the C4-position, at more downstream steps of phytosterol biosynthesis (Fig. 4). The tomato cholesterol biosynthetic pathway involves another pair of SMOs (SMO3 and SMO4 that evolved from SMO1 and SMO2 respectively) at analogous positions in the cholesterol pathway (Fig. 4) (Sonawane et al., 2016).

Using tissue cultures of smo1-1smo1-2/+ roots, and virus-induced gene silencing (VIGS) it was shown that smo1 activity is required for biosynthesis of $\beta$-sitosterol, stigmasterol, campesterol and cholesterol, which was accompanied with accumulation of the SMO1 substrate 24-methylenecycloartenol and its precursor cycloartenol (Darnet and Rahier, 2004; Song et al., 2019). Moreover, VIGS of SMO2 genes led to accumulation of $4 \alpha-$ methylsterols in N. benthamiana leaves (Darnet and Rahier, 2004), which could be confirmed by analyzing smo2-1smo2-2/+ and smo2-1/+ smo2-2 (Zhang et al., 2016). Jointly, these knock-down strategies provide in planta support for their biochemical function. 
Plant CSDs have been shown to complement ergosterol biosynthesis in erg26 yeast mutants (Rahier et al., 2006), putatively acting in conjunction with the distinct plant SMOtypes in phytosterol and cholesterol biosynthesis (Rahier et al., 2006; Sonawane et al., 2016). Additionally, silencing of a putative $S R$ gene in tomato further supported a role of distinct C4-demethylation complexes involved in phytosterol and cholesterol biosynthesis (Sonawane et al., 2016).

Importantly, despite their ability to complement the erg25 mutant, plant SMOs display marked differences in substrate specificity, and are 500-fold less sensitive to the antifungal SMO inhibitor APB (6-Amino-2- $n$-pentylthiobenzothiazole) (Darnet and Rahier, 2003). This suggests that new and subtype-specific SMO inhibitors need to be developed to target these steps in phytosterol and cholesterol biosynthesis. Additionally, inhibitors of CSD and SR activity that were recently identified, remain to be evaluated for interference with C4demethylation in plants (Darnet and Schaller, 2019).

\section{Processing of C4-methylsterols- cycloeucalenol cycloisomerase (CPI1)}

The opening of the cyclopropane ring of cycloeucalenol by CYCLOEUCALENOL CYCLOISOMERASE1 (CPI1) subsequently leads to the production of obtusifoliol (Fig. 4). Consistent with its biochemical function, the cpi1 mutant is characterized by increased levels of cycloeucalenol and a strong decrease in $\beta$-sitosterol and stigmasterol (Men et al., 2008). Additionally the mutant accumulates some abnormal sterols, such as 24 -methylpollinastanol. Silencing of the single copy of $\mathrm{CPI}$ in tomato revealed an analogous biochemical function in cholesterol biosynthesis, as indicated by the accumulation of the 31-norcycloartenol substrate (Sonawane et al., 2016).

Currently, no specific CPI inhibitors are available. CPI1 catalyzes similar reactions as C-14 sterol reductase and C-8,7 sterol isomerase, making them shared targets for molecular inhibition by morpholines such as fenpropimorph (Taton et al., 1987). Moreover CPI was found to be a secondary target of the CAS1 inhibitor LDAO (Darnet et al., 2020).

\section{Processing of C4-methylsterols - obtusifoliol 14a-demethylase (CYP51G1)}

Obtusifoliol then undergoes demethylation and reduction at its C-14 position, via an

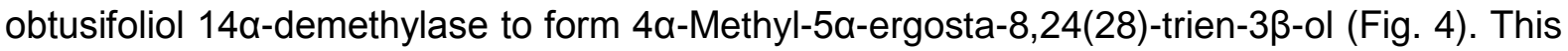
enzymatic activity is exerted by CYP51, a cytochrome P450-dependent monooxygenase that is conserved across phyla (Lepesheva and Waterman, 2007). Arabidopsis contains a single, functional sterol C14-demethylase, CYP51 (renamed CYP51G1; (Bak et al., 2011)), that can 
complement the erg11 yeast mutant, deficient in lanosterol C14-demethylase (Kushiro et al., 2001).

Consistent with its metabolic function in phytosterol biosynthesis, a cyp51 mutant accumulated its substrate obtusifoliol, at the expense of downstream phytosterols, campesterol, $\beta$-sitosterol and stigmasterol (Kim et al., 2005). CYP51 also catalyzes cholesterol biosynthesis at an analogous step in Arabidopsis, tomato and $N$. benthamiana (Fig. 4)(Kim et al., 2005; Sonawane et al., 2016).

CYP51 belongs to the cytochrome P450s, a large group of enzymes that are often sensitive to two types of azoles; the imidazoles, such as clotrimazole, oxiconazole, and ketoconazole and the triazoles, such as triadimenol, voriconazole and fluconazole. These are nitrogen-containing heterocyclic compounds that non-competitively bind to the ferric ion of the heme group of the cytochrome P450 thus preventing it from binding its substrate (Warrilow et al., 2013). Despite being primarily used as fungicides, several azoles also cause growth inhibition in plants, which may be due to interference with downstream BR biosynthesis (Rozhon et al., 2013). The fungicidal activity of azoles derives from a combination of depleting ergosterol, and accumulating the toxic obtusifoliol-metabolite $14 \alpha-$ methyl ergosta 8,24(28)-dien-3ß-6a-diol (Martel et al., 2010a; Martel et al., 2010b). One of the potential problems of working with azoles is their promiscuity towards diverse CYPs, and thus their potential for off-target effects, especially at higher concentrations, which are often needed to obtain a significant inhibitory effect on phytosterol biosynthesis in plants and diatoms (Fabris et al., 2014). Indeed, uniconazole does not only inhibit CYP707A, that is involved in abscisic acid catabolism, it can also inhibit CYP90B1/DWARF4, that is involved in brassinosteroid biosynthesis (Fujiyama et al., 2019).

\section{Processing of C4-methylsterols - sterol C14-reductase (FACKEL /FK) and C- $\Delta 8, \Delta 7$ sterol isomerase (HYDRA1/HYD1)}

In the subsequent steps a sterol C14 reductase generates $4 \alpha$-methylfecosterol that is converted into $4 \alpha$-methylenelophenol by a C- $\Delta 8, \Delta 7$ sterol isomerase (Fig. 4). Both enzymatic steps are encoded by single genes in Arabidopsis, FACKEL/HYDRA2 (FK/HYD2) and HYDRA1 (HYD1) respectively, and in tomato (Sonawane et al., 2016). Both types of enzymes can complement the ergosterol biosynthesis in corresponding mutant yeast strains, erg24 (Schrick et al., 2000) and erg2 (Grebenok et al., 1998; Sonawane et al., 2016) respectively. Moreover, the sterol profiles are markedly similar, showing defects that are more prominent in actively dividing mutant calli than in the corresponding mutant seedlings 
(Schrick et al., 2000; Schrick et al., 2002; Souter et al., 2002). Calli of fk and hyd1 are mainly affected in their campesterol levels, and to a lesser extend in their $\beta$-sitosterol levels, while stigmasterol levels remaini largely unaffected and cholesterol levels even increase (Schrick et al., 2000; Schrick et al., 2002). The largely specific effect on campesterol is difficult to explain as the other phytosterols and cholesterol all depend on precursors generated via these single gene-encoded enzymatic activities (Sonawane et al., 2016).

Together with CPI, FK/HYD2 and HYD1 are targeted by a largely overlapping pharmacology (Fig. 4). An important class of inhibitors that target these enzymes are the morpholine fungicides, such as fenpropimorph. These compounds inhibit C-8,7 sterol isomerases ( $\mathrm{nM}$ concentrations) and/or $\mathrm{C} 14$ sterol reductases ( $\mu \mathrm{M}$ concentration) in fungi and yeast (Mercer, 1993). In plants, morpholines inhibit HYD1, FK and CPI (He et al., 2003; Rahier et al., 1986; Taton et al., 1987). While fenpropimorph is the most commonly used morpholine in plants, it requires relatively high concentrations to function (30-100 $\mu \mathrm{M})$, it is unstable and relatively expensive. Plants treated with morpholines have a disturbed sterol profile and growth impairments, similar to those observed in mutants defective in the targeted enzymes (He et al., 2003).

A strong, more specific inhibitor of C-14 sterol reductases is the antifungal agent 15aza-24-methylene-D-homocholesta-8,14-dien-3ß-ol (15-azasterol) (Fig. 4), which causes similar changes in the sterol profiles as observed in the fk mutant (Schrick et al., 2002).

\section{Final processing steps in phytosterol and cholesterol biosynthesis}

After the second C4-demethylation (cfr. C4-demethylation), the subsequent production of campesterol and stigmasterol is effected by three enzymes acting in both branches of the pathway at corresponding steps: $\Delta^{7}$-sterol-C5-desaturase (C5-SD1) (in Arabidopsis DWARF7/STEROL1 (DWF7/STE1), sterol $\Delta^{7}$-reductase (7-DR1) (in Arabidopsis, DWARF5 (DWF5)) and $\Delta^{24}$-sterol- $\Delta^{24}$-reductase/SIDE CHAIN REDUCTASE1 (SSR1) (in Arabidopsis DIMINUTO/DWARF1 (DIM/DWF1) (Fig. 5). Cholesterol biosynthesis in tomato involves the diverged SMO4, C5-SD-2 and 7-DR-2 (Sonawane et al., 2016) (Fig. 5).

The genes DWARF7/STEROL1 (DWF7/STE1), DWARF5 (DWF5) and DIMINUTO/DWARF1 (DIM/DWF1) encode the C5-SD1, 7-DR1 and the SSR1 enzymes in Arabidopsis, and are required for the production of campesterol and $\beta$-sitosterol. The $d w f 7 /$ ste 1 mutants accumulate $\Delta 7$-sterols, and are strongly defective in campesterol, $\beta$ sitosterol and stigmasterol (Silvestro et al., 2013). The $d w f 5$ mutant also accumulates $\Delta 7$, $\Delta 5,7$ and $\Delta 8$-sterols and has strongly reduced levels of campesterol, $\beta$-sitosterol and stigmasterol (Silvestro et al., 2013). In dim/dwf1 mutants, campesterol, $\beta$-sitosterol and 
stigmasterol were reduced, while the $\beta$-sitosterol and campesterol precursors isofucosterol, and 24-methylene cholesterol, respectively, were increased (Klahre et al., 1998). Interestingly, besides acting as a sterol C24-reductase, DWF1 was found to also display brassinosteroid C24-reductase activity (Youn et al., 2018). Currently, no inhibitors are available for this part of the phytosterol biosynthesis pathway.

In the ethylsterol branch, $\beta$-sitosterol undergoes $\mathrm{C}-22$ desaturation by the $\mathrm{C}-22$ sterol desaturase CYP710A1, resulting in the end-product of this pathway: stigmasterol (Morikawa et al., 2006). However, not many details are known about this desaturation reaction in higher plants. Interestingly, in Arabidopsis, a second CYP710 enzyme (CYP710A2) is also able to produce stigmasterol from $\beta$-sitosterol, and can also produce brassicasterol from 24-epicampesterol (Benveniste, 2002; Morikawa et al., 2006). Given that CYP710 belongs to the cytochrome P450 family, it is likely that this enzyme is sensitive to azoles, as indicated in the CYP51 section.

\section{Sterol conjugation and oxidation}

Besides through biosynthesis, sterol levels can be regulated via conjugation, to form fatty acid acyl sterol esters (SE), steryl glucosides (SG) and acyl steryl glucosides (ASG). The SEs are major constituents of cytosolic lipid droplets (Shimada et al., 2019) and are proposed to serve as storage forms that can be rapidly mobilized. SGs and ASGs contribute to the membrane organization eg. as important constituents of plasma membrane microdomains. For details about the biosynthesis and physiological function of SEs, SGs and ASGs, we refer the reader to some excellent recent reviews (Ferrer et al., 2017; Korber et al., 2017; Mamode Cassim et al., 2019; Zhang et al., 2020)

While the hydrolases and glycosidases remain elusive, several other key biosynthetic enzymes have been identified and characterized. In brief, SEs are formed by activities by two distinct types of acyltransferases: acylCoA:sterol acyltransferases (ASAT) and phospholipid:sterol acyltransferases (PSAT), using respectively long-chain acyl-CoA and unsaturated fatty acyl groups from phospholipids as a donors (Chen et al., 2007). Although belonging to a family of six related proteins, Arabidopsis is thought to have only one PSAT (PSAT1) (Ferrer et al., 2017). Similarly, only one member of the membrane-bound Oacyltransferases (MBOAT) was found to display ASAT activity (Chen et al., 2007). Mutants in psat1 have early leaf senescence but asat1 mutants lack an obvious morphological phenotype (Bouvier-Nave et al., 2010). At the level of SE formation, analysis of these mutants showed major contributions of PSAT1 over ASAT1. 
Several inhibitors of human ASAT enzymes have been identified (Ohshiro et al., 2020a; Ohshiro et al., 2020b; Ohtawa et al., 2018), but their activity and specificity in plants remains to be demonstrated. The recently resolved structure of human Sterol Oacyltransferase 1 revealed that the small molecule mode $\mathrm{Cl}-976$ blocks the accessibility of several active site residues (Guan et al., 2020), and may serve as a template for docking analyses to assess the activity of such inhibitors on plant enzymes.

Two steryl glycosyl transferases (UGT80A2/B1), both related to the yeast steryl glycosl transferase UGT51A1, are jointly required for SE formation in Arabidopsis (Stucky et al., 2015), by adding a sugar moiety, usually glucose, to the C3-hydroxyl group of the sterol. However, while steryl glycosyl acyltransferase activity could be detected, its molecular constituents remain to be identified. Mutants defective in the SGT enzymes, display moderate phenotypes, ranging from some seed coat and embryo phenotypes to a reduced root elongation (Stucky et al., 2015). Recently, reduced root hair production in ugt80b1 mutants was connected to mislocalisation of the root hair cell fate regulator SCRAMBLED (Pook et al., 2017). The residual SG and ASG accumulation in these mutants suggests additional, redundant SGT enzyme activities remain to be identified (Stucky et al., 2015). Also for UDP-glycosyl transferases, several inhibitors can be found (Lv et al., 2019; Oda et al., 2015), that were not yet used or evaluated to inhibit steryl glycosyl transferase activities in plants.

\section{Conclusions}

Deriving from an ancestral pathway, each of the three eukaryotic kingdoms gave sterol biosynthesis its own flavor with an end-result that is tailored to the specific needs inherent to the adopted life-style. In plants, animals and fungi, the sterol composition is a key determinant of the physico-chemical properties and spatial organization of membranes. Additionally, sterols have a serious impact on physiology and signaling processes as precursors of potent hormones, such as brassinolide (Vriet et al., 2013). However, it is becoming more and more obvious that sterols are key components of plant development, in addition to their role in brassinolide biosynthesis (Boutté and Jaillais, 2020). Currently, most work has been done using Arabidopsis as a model. It is, however, easy to envision that much remains to be learnt about the roles of the multitude of diverse sterols that exists within the green lineage. The most straightforward way to achieve this is through interference with the biosynthetic pathway using inhibitors. Several enzymatic steps are sufficiently conserved to justify the use of inhibitors that were developed in yeast and mammals, while others are not. In combination with a tremendous diversification of the enzymes, and even novel 
enzymes being recruited as seen in diatoms, it is clear that a more targeted pharmacology is needed to meet specific needs. On the other hand, the existence of plant-specific, or even species-specific enzymatic activities represents attractive opportunities for the development of highly selective herbicides.

Most of our inferences about the physiological and cell biological roles of phytosterols derive from studies in mutants that accumulate C4-dimethylated sterol biosynthesis intermediates. These mutants, such as smt1 (Diener et al., 2000; Schrick et al., 2002; Willemsen et al., 2003), smo1-1smo1-2 (Song et al., 2019), cyp51 (Kim et al., 2005), fk/hyd2 (Schrick et al., 2000), hyd1 (Topping et al., 1997), cpi1 (Men et al., 2008), smt2smt3 (Carland et al., 2010; Short et al., 2018; Souter et al., 2002), and smo2-1smo2-2 (Zhang et al., 2016), display severe developmental defects, and are often associated with misregulated auxin and cytokinin homeostasis, and with defects in endocytosis and cellular polarization mechanisms. However, mutants defective in later steps of sterol biosynthesis and not accumulating C4-(di)-methylated sterol biosynthesis intermediates, dwf7/ste1, dwf5 and dim/dwf1 mainly display typical brassinosteroid deficiency phenotypes, that can be partially reversed by exogenous application of brassinolide (Vriet et al., 2013). This discrepancy in phenotypes indicates that the observed, strong, phenotypes reflect a specific toxicity, or signaling function related to the accumulation of the sterol biosynthesis intermediates, rather than to defects in phytosterols. This calls for caution when inferring physiological roles of sterols in plants, as most available inhibitors result in accumulation of C4-(di)methylated sterol biosynthesis intermediates that have severe impact on biological processes in plants, animals and yeast (Darnet and Schaller, 2019). 
Acknowledgements: K.D.V. is funded by the Special Research Fund Ghent University (01D25813).

Author Contributions: K.D.V and S.V. conceptualized the review; All authors contributed to the writing and revision of the manuscript

Conflicts of Interest: The authors declare no conflicts of interest 


\section{References}

Babiychuk E, Bouvier-Nave P, Compagnon V, Suzuki M, Muranaka T, Van Montagu M, Kushnir S, Schaller H. 2008. Allelic mutant series reveal distinct functions for Arabidopsis cycloartenol synthase 1 in cell viability and plastid biogenesis. Proceedings of the National Academy of Sciences of the United States of America 105, 3163-3168.

Bak S, Beisson F, Bishop G, Hamberger B, Hofer R, Paquette S, Werck-Reichhart D. 2011. Cytochromes p450. Arabidopsis Book 9, e0144.

Banerjee A, Sharkey TD. 2014. Methylerythritol 4-phosphate (MEP) pathway metabolic regulation. Natural Products Report 31, 1043-1055.

Baxter A, Fitzgerald BJ, Hutson JL, McCarthy AD, Motteram JM, Ross BC, Sapra M, Snowden MA, Watson NS, Williams RJ, et al. 1992. Squalestatin 1, a potent inhibitor of squalene synthase, which lowers serum cholesterol in vivo. The Journal of biological chemistry 267, 11705-11708.

Behrman EJ, Gopalan V. 2005. Cholesterol and plants. Journal of Chemical Education 82, 1791-1793. Benveniste P. 2002. Sterol metabolism. The arabidopsis book 1, e0004.

Benveniste P. 2004. Biosynthesis and accumulation of sterols. Annual review of plant biology 55, 429-457.

Bergstrom JD, Kurtz MM, Rew DJ, Amend AM, Karkas JD, Bostedor RG, Bansal VS, Dufresne C, VanMiddlesworth FL, Hensens OD, et al. 1993. Zaragozic acids: a family of fungal metabolites that are picomolar competitive inhibitors of squalene synthase. Proceedings of the National Academy of Sciences of the United States of America 90, 80-84.

Bode HB, Zeggel B, Silakowski B, Wenzel SC, Reichenbach H, Muller R. 2003. Steroid biosynthesis in prokaryotes: identification of myxobacterial steroids and cloning of the first bacterial 2,3(S)oxidosqualene cyclase from the myxobacterium Stigmatella aurantiaca. Mol Microbiol 47, 471-481.

Boutté Y, Grebe M. 2009. Cellular processes relying on sterol function in plants. Current Opinion Plant Biology 12, 705-713.

Boutté Y, Jaillais Y. 2020. Metabolic Cellular Communications: Feedback Mechanisms between Membrane Lipid Homeostasis and Plant Development. Developmental Cell 54, 171-182.

Bouvier-Nave P, Berna A, Noiriel A, Compagnon V, Carlsson AS, Banas A, Stymne S, Schaller H. 2010. Involvement of the phospholipid sterol acyltransferase1 in plant sterol homeostasis and leaf senescence. Plant Physiology 152, 107-119.

Brenner WG, Leuendorf JE, Cortleven A, Martin LBB, Schaller H, Schmulling T. 2017. Analysis of CFB, a cytokinin-responsive gene of Arabidopsis thaliana encoding a novel F-box protein regulating sterol biosynthesis. Journal of Experimental Botany 68, 2769-2785.

Busquets A, Keim V, Closa M, del Arco A, Boronat A, Arro M, Ferrer A. 2008. Arabidopsis thaliana contains a single gene encoding squalene synthase. Plant molecular biology 67, 25-36.

Carland F, Fujioka S, Nelson T. 2010. The sterol methyltransferases SMT1, SMT2, and SMT3 influence Arabidopsis development through nonbrassinosteroid products. Plant physiology 153, 741 756.

Chen M, Chen J, Luo N, Qu R, Guo Z, Lu S. 2018. Cholesterol accumulation by suppression of SMT1 leads to dwarfism and improved drought tolerance in herbaceous plants. Plant, Cell and Environment 41, 1417-1426.

Chen Q, Steinhauer L, Hammerlindl J, Keller W, Zou J. 2007. Biosynthesis of phytosterol esters: identification of a sterol o-acyltransferase in Arabidopsis. Plant Physiology 145, 974-984.

Closa M, Vranova E, Bortolotti C, Bigler L, Arro M, Ferrer A, Gruissem W. 2010. The Arabidopsis thaliana FPP synthase isozymes have overlapping and specific functions in isoprenoid biosynthesis, and complete loss of FPP synthase activity causes early developmental arrest. Plant Journal 63, 512525.

Darnet S, Bard M, Rahier A. 2001. Functional identification of sterol-4alpha-methyl oxidase cDNAs from Arabidopsis thaliana by complementation of a yeast erg25 mutant lacking sterol-4alpha-methyl oxidation. FEBS Letters 508, 39-43. 
Darnet S, Martin LBB, Mercier P, Bracher F, Geoffroy P, Schaller H. 2020. Inhibition of Phytosterol Biosynthesis by Azasterols. Molecules 25.

Darnet S, Rahier A. 2003. Enzymological properties of sterol-C4-methyl-oxidase of yeast sterol biosynthesis. Biochimica Biophysica Acta 1633, 106-117.

Darnet S, Rahier A. 2004. Plant sterol biosynthesis: identification of two distinct families of sterol 4alpha-methyl oxidases. The Biochemical journal 378, 889-898.

Darnet S, Schaller H. 2019. Metabolism and Biological Activities of 4-Methyl-Sterols. Molecules 24. Davies JT, Delfino SF, Feinberg CE, Johnson MF, Nappi VL, Olinger JT, Schwab AP, Swanson HI. 2016. Current and Emerging Uses of Statins in Clinical Therapeutics: A Review. Lipid insights 9, 13-29. Diener AC, Li H, Zhou W, Whoriskey WJ, Nes WD, Fink GR. 2000. Sterol methyltransferase 1 controls the level of cholesterol in plants. The Plant cell 12, 853-870.

Doblas VG, Amorim-Silva V, Pose D, Rosado A, Esteban A, Arro M, Azevedo H, Bombarely A, Borsani O, Valpuesta V, Ferrer A, Tavares RM, Botella MA. 2013. The SUD1 gene encodes a putative E3 ubiquitin ligase and is a positive regulator of 3-hydroxy-3-methylglutaryl coenzyme a reductase activity in Arabidopsis. The Plant cell 25, 728-743.

Fabris M, Matthijs M, Carbonelle S, Moses T, Pollier J, Dasseville R, Baart GJ, Vyverman W, Goossens A. 2014. Tracking the sterol biosynthesis pathway of the diatom Phaeodactylum tricornutum. The New phytologist 204, 521-535.

Ferrer A, Altabella T, Arro M, Boronat A. 2017. Emerging roles for conjugated sterols in plants. Progress in Lipid Research 67, 27-37.

Fujiyama K, Hino T, Kanadani M, Watanabe B, Jae Lee H, Mizutani M, Nagano S. 2019. Structural insights into a key step of brassinosteroid biosynthesis and its inhibition. Nature Plants 5, 589-594.

Galea AM, Brown AJ. 2009. Special relationship between sterols and oxygen: were sterols an adaptation to aerobic life? Free Radical Biology and Medicine 47, 880-889.

Gas-Pascual E, Berna A, Bach TJ, Schaller H. 2014. Plant oxidosqualene metabolism: cycloartenol synthase-dependent sterol biosynthesis in Nicotiana benthamiana. PloS one 9, e109156.

Gas-Pascual E, Simonovik B, Schaller H, Bach TJ. 2015. Inhibition of Cycloartenol Synthase (CAS) Function in Tobacco BY-2 Cells. Lipids 50, 761-772.

Grebenok RJ, Ohnmeiss TE, Yamamoto A, Huntley ED, Galbraith DW, Della Penna D. 1998. Isolation and characterization of an Arabidopsis thaliana C-8,7 sterol isomerase: functional and structural similarities to mammalian C-8,7 sterol isomerase/emopamil-binding protein. Plant Molecular Biology 38, 807-815.

Guan C, Niu Y, Chen SC, Kang Y, Wu JX, Nishi K, Chang CCY, Chang TY, Luo T, Chen L. 2020. Structural insights into the inhibition mechanism of human sterol O-acyltransferase 1 by a competitive inhibitor. Nature Communications 11, 2478.

Guo DA, Venkatramesh M, Nes WD. 1995. Developmental regulation of sterol biosynthesis in Zea mays. Lipids 30, 203-219.

Hartmann MA, Wentzinger L, Hemmerlin A, Bach TJ. 2000. Metabolism of farnesyl diphosphate in tobacco BY-2 cells treated with squalestatin. Biochemical Society transactions 28, 794-796.

He JX, Fujioka S, Li TC, Kang SG, Seto H, Takatsuto S, Yoshida S, Jang JC. 2003. Sterols regulate development and gene expression in Arabidopsis. Plant physiology 131, 1258-1269.

Henry LK, Gutensohn M, Thomas ST, Noel JP, Dudareva N. 2015. Orthologs of the archaeal isopentenyl phosphate kinase regulate terpenoid production in plants. Proceedings of the National Academy of Sciences of the United States of America 112, 10050-10055.

Henry LK, Thomas ST, Widhalm JR, Lynch JH, Davis TC, Kessler SA, Bohlmann J, Noel JP, Dudareva N. 2018. Contribution of isopentenyl phosphate to plant terpenoid metabolism. Nature plants 4, 721-729.

Huang AC, Jiang T, Liu YX, Bai YC, Reed J, Qu B, Goossens A, Nutzmann HW, Bai Y, Osbourn A. 2019. A specialized metabolic network selectively modulates Arabidopsis root microbiota. Science 364.

Istvan ES, Deisenhofer J. 2001. Structural mechanism for statin inhibition of HMG-CoA reductase. Science 292, 1160-1164. 
Kasahara H, Hanada A, Kuzuyama T, Takagi M, Kamiya Y, Yamaguchi S. 2002. Contribution of the mevalonate and methylerythritol phosphate pathways to the biosynthesis of gibberellins in Arabidopsis. Journal Biological Chemistry 277, 45188-45194.

Kim HB, Schaller H, Goh CH, Kwon M, Choe S, An CS, Durst F, Feldmann KA, Feyereisen R. 2005. Arabidopsis cyp51 mutant shows postembryonic seedling lethality associated with lack of membrane integrity. Plant Physiology 138, 2033-2047.

Klahre U, Noguchi T, Fujioka S, Takatsuto S, Yokota T, Nomura T, Yoshida S, Chua NH. 1998. The Arabidopsis DIMINUTO/DWARF1 gene encodes a protein involved in steroid synthesis. The Plant cell 10, 1677-1690.

Kobayashi K, Kobayashi K, Yamaguchi H, Miyagi Inoue Y, Takagi K, Fushihara K, Seki H, Suzuki M, Nagata N, Muranaka T. 2017. Platform for "Chemical Metabolic Switching" to Increase Sesquiterpene Content in Plants. Plant Biotechnology 34, 65-69.

Kolesnikova MD, Xiong Q, Lodeiro S, Hua L, Matsuda SP. 2006. Lanosterol biosynthesis in plants. Archives of biochemistry and biophysics 447, 87-95.

Korber M, Klein I, Daum G. 2017. Steryl ester synthesis, storage and hydrolysis: A contribution to sterol homeostasis. Biochimica Biophysica Acta Molecular and Cell Biology of Lipids 1862, 15341545.

Kribii R, Arro M, Del Arco A, Gonzalez V, Balcells L, Delourme D, Ferrer A, Karst F, Boronat A. 1997. Cloning and characterization of the Arabidopsis thaliana SQS1 gene encoding squalene synthase-involvement of the C-terminal region of the enzyme in the channeling of squalene through the sterol pathway. European Journal of Biochemistry 249, 61-69.

Kushiro M, Nakano T, Sato K, Yamagishi K, Asami T, Nakano A, Takatsuto S, Fujioka S, Ebizuka Y, Yoshida S. 2001. Obtusifoliol 14alpha-demethylase (CYP51) antisense Arabidopsis shows slow growth and long life. Biochemical and Biophysical Research Communications 285, 98-104.

Laranjeira S, Amorim-Silva V, Esteban A, Arro M, Ferrer A, Tavares RM, Botella MA, Rosado A, Azevedo H. 2015. Arabidopsis Squalene Epoxidase 3 (SQE3) Complements SQE1 and Is Important for Embryo Development and Bulk Squalene Epoxidase Activity. Molecular plant 8, 1090-1102.

Laule O, Furholz A, Chang HS, Zhu T, Wang X, Heifetz PB, Gruissem W, Lange M. 2003. Crosstalk between cytosolic and plastidial pathways of isoprenoid biosynthesis in Arabidopsis thaliana. Proceedings of the National Academy of Sciences of the United States of America 100, 6866-6871.

Leber R, Fuchsbichler S, Klobucnikova V, Schweighofer N, Pitters E, Wohlfarter K, Lederer M, Landl K, Ruckenstuhl C, Hapala I, Turnowsky F. 2003. Molecular mechanism of terbinafine resistance in Saccharomyces cerevisiae. Antimicrobial Agents and Chemotherapy 47, 3890-3900.

Lepesheva GI, Waterman MR. 2007. Sterol 14alpha-demethylase cytochrome P450 (CYP51), a P450 in all biological kingdoms. Biochimica et biophysica acta 1770, 467-477.

Li GL, Guo WJ, Wang GB, Wang RR, Hou YX, Liu K, Liu Y, Wang W. 2017. Sterols from the Green Alga Ulva australis. Marine Drugs 15.

Lohr M, Schwender J, Polle JE. 2012. Isoprenoid biosynthesis in eukaryotic phototrophs: a spotlight on algae. Plant Science 185-186, 9-22.

Lopes G, Sousa C, Bernardo J, Andrade PB, Valentao P, Ferreres F, Mouga T. 2011. Sterol Profiles in 18 Macroalgae of the Portuguese Coast(1). Journal of Phycology 47, 1210-1218.

Lv X, Xia Y, Finel M, Wu J, Ge G, Yang L. 2019. Recent progress and challenges in screening and characterization of UGT1A1 inhibitors. Acta Pharmaceutica Sinica B 9, 258-278.

Mamode Cassim A, Gouguet P, Gronnier J, Laurent N, Germain V, Grison M, Boutté Y, GerbeauPissot P, Simon-Plas F, Mongrand S. 2019. Plant Lipids: Key players of plasma membrane organisation and function. Progress in lipid research 73, 1-27.

Manzano D, Andrade P, Caudepon D, Altabella T, Arro M, Ferrer A. 2016. Suppressing Farnesyl Diphosphate Synthase Alters Chloroplast Development and Triggers Sterol-Dependent Induction of Jasmonate- and Fe-Related Responses. Plant Physiology 172, 93-117.

Martel CM, Parker JE, Bader O, Weig M, Gross U, Warrilow AG, Kelly DE, Kelly SL. 2010a. A clinical isolate of Candida albicans with mutations in ERG11 (encoding sterol 14alpha-demethylase) and 
ERG5 (encoding C22 desaturase) is cross resistant to azoles and amphotericin B. Antimicrobial Agents and Chemotherapy 54, 3578-3583.

Martel CM, Parker JE, Warrilow AG, Rolley NJ, Kelly SL, Kelly DE. 2010b. Complementation of a Saccharomyces cerevisiae ERG11/CYP51 (sterol 14alpha-demethylase) doxycycline-regulated mutant and screening of the azole sensitivity of Aspergillus fumigatus isoenzymes CYP51A and CYP51B. Antimicrobial Agents and Chemotherapy 54, 4920-4923.

Men S, Boutte Y, Ikeda Y, Li X, Palme K, Stierhof YD, Hartmann MA, Moritz T, Grebe M. 2008. Sterol-dependent endocytosis mediates post-cytokinetic acquisition of PIN2 auxin efflux carrier polarity. Nature cell biology 10, 237-244.

Mercer El. 1993. Inhibitors of sterol biosynthesis and their applications. Progress in Lipid Research 32, 357-416.

Mialoundama AS, Jadid N, Brunel J, Di Pascoli T, Heintz D, Erhardt M, Mutterer J, Bergdoll $M$, Ayoub D, Van Dorsselaer A, Rahier A, Nkeng P, Geoffroy P, Miesch M, Camara B, Bouvier F. 2013. Arabidopsis ERG28 tethers the sterol C4-demethylation complex to prevent accumulation of a biosynthetic intermediate that interferes with polar auxin transport. Plant Cell 25, 4879-4893.

Miettinen K, Inigo S, Kreft L, Pollier J, De Bo C, Botzki A, Coppens F, Bak S, Goossens A. 2018. The TriForC database: a comprehensive up-to-date resource of plant triterpene biosynthesis. Nucleic Acids Research 46, D586-D594.

Morikawa T, Mizutani M, Aoki N, Watanabe B, Saga H, Saito S, Oikawa A, Suzuki H, Sakurai N, Shibata D, Wadano A, Sakata K, Ohta D. 2006. Cytochrome P450 CYP710A encodes the sterol C-22 desaturase in Arabidopsis and tomato. The Plant cell 18, 1008-1022.

Mouritsen OG. 2005. Cholesterol on the scene. Life-as a matter of fat: the emerging science of lipidomics, 149-157.

Nowosielski M, Hoffmann M, Wyrwicz LS, Stepniak P, Plewczynski DM, Lazniewski M, Ginalski K, Rychlewski L. 2011. Detailed mechanism of squalene epoxidase inhibition by terbinafine. Journal of Chemical Information and Modeling 51, 455-462.

Oda S, Fujiwara R, Kutsuno Y, Fukami T, Itoh T, Yokoi T, Nakajima M. 2015. Targeted screen for human UDP-glucuronosyltransferases inhibitors and the evaluation of potential drug-drug interactions with zafirlukast. Drug Metabolism and Dispositino 43, 812-818.

Ohshiro T, Imuta S, Hijikuro I, Yagyu H, Takahashi T, Doi T, Ishibashi S, Tomoda H. 2020a. The Antiatherogenic Activity of Beauveriolide Derivative BVD327, a Sterol O-Acyltransferase 2-Selective Inhibitor, in Apolipoprotein E Knockout Mice. Biological and Pharmaceutical Bulletin 43, 951-958.

Ohshiro T, Morita H, Nur EAA, Hosoda K, Uchida R, Tomoda H. 2020b. Voluhemins, new inhibitors of sterol O-acyltransferase, produced by Volutella citrinella BF-0440. Journal of Antibiotics. https://doi.org/10.1038/s41429-020-0327-0

Ohtawa M, Arima S, Ichida N, Terayama T, Ohno H, Yamazaki T, Ohshiro T, Sato N, Omura S, Tomoda H, Nagamitsu T. 2018. Design and Synthesis of A-Ring Simplified Pyripyropene A Analogues as Potent and Selective Synthetic SOAT2 Inhibitors. ChemMedChem 13, 411-421.

Ohyama K, Suzuki M, Kikuchi J, Saito K, Muranaka T. 2009. Dual biosynthetic pathways to phytosterol via cycloartenol and lanosterol in Arabidopsis. Proceedings of the National Academy of Sciences of the United States of America 106, 725-730.

Pollier J, Vancaester E, Kuzhiumparambil U, Vickers CE, Vandepoele K, Goossens A, Fabris M. 2019. A widespread alternative squalene epoxidase participates in eukaryote steroid biosynthesis. Nature microbiology 4, 226-233.

Pook VG, Nair M, Ryu K, Arpin JC, Schiefelbein J, Schrick K, DeBolt S. 2017. Positioning of the SCRAMBLED receptor requires UDP-Glc:sterol glucosyltransferase 80B1 in Arabidopsis roots. Scientific Reports 7, 5714.

Posé D, Castanedo I, Borsani O, Nieto B, Rosado A, Taconnat L, Ferrer A, Dolan L, Valpuesta V, Botella MA. 2009. Identification of the Arabidopsis dry2/sqe1-5 mutant reveals a central role for sterols in drought tolerance and regulation of reactive oxygen species. The Plant Journal 59, 63-76. 
Rahier A, Darnet S, Bouvier F, Camara B, Bard M. 2006. Molecular and enzymatic characterizations of novel bifunctional 3beta-hydroxysteroid dehydrogenases/C-4 decarboxylases from Arabidopsis thaliana. Journal of Biological Chemistry 281, 27264-27277.

Rahier A, Schmitt P, Huss B, Benveniste P, Pommer EH. 1986. Chemical-Structure Activity Relationships of the Inhibition of Sterol Biosynthesis by N-Substituted Morpholines in Higher-Plants. Pesticide Biochemistry and Physiology 25, 112-124.

Rampen SW, Abbas BA, Schouten S, Sinninghe Damste JS. 2010. A comprehensive study of sterols in marine diatoms (Bacillariophyta): Implications for their use as tracers for diatom productivity. Limnology and Oceanography 55, 91-105.

Rasbery JM, Shan H, LeClair RJ, Norman M, Matsuda SP, Bartel B. 2007. Arabidopsis thaliana squalene epoxidase 1 is essential for root and seed development. The Journal of biological chemistry 282, 17002-17013.

Renard D, Perruchon J, Giera M, Muller J, Bracher F. 2009. Side chain azasteroids and thiasteroids as sterol methyltransferase inhibitors in ergosterol biosynthesis. Bioorg Med Chem 17, 8123-8137.

Rivas-Marin E, Stettner S, Gottshall EY, Santana-Molina C, Helling M, Basile F, Ward NL, Devos DP. 2019. Essentiality of sterol synthesis genes in the planctomycete bacterium Gemmata obscuriglobus. Nature Communications 10, 2916.

Rozhon W, Husar S, Kalaivanan F, Khan M, Idlhammer M, Shumilina D, Lange T, Hoffmann T, Schwab W, Fujioka S, Poppenberger B. 2013. Genetic variation in plant CYP51s confers resistance against voriconazole, a novel inhibitor of brassinosteroid-dependent sterol biosynthesis. PloS one $\mathbf{8}$, e53650.

Saenz JP, Grosser D, Bradley AS, Lagny TJ, Lavrynenko O, Broda M, Simons K. 2015. Hopanoids as functional analogues of cholesterol in bacterial membranes. Proc Natl Acad Sci U S A 112, 1197111976.

Sawai S, Akashi T, Sakurai N, Suzuki H, Shibata D, Ayabe S, Aoki T. 2006. Plant lanosterol synthase: divergence of the sterol and triterpene biosynthetic pathways in eukaryotes. Plant \& cell physiology 47, 673-677.

Sawai S, Ohyama K, Yasumoto S, Seki H, Sakuma T, Yamamoto T, Takebayashi Y, Kojima M, Sakakibara H, Aoki T, Muranaka T, Saito K, Umemoto N. 2014. Sterol side chain reductase 2 is a key enzyme in the biosynthesis of cholesterol, the common precursor of toxic steroidal glycoalkaloids in potato. Plant Cell 26, 3763-3774.

Schaeffer A, Bronner R, Benveniste P, Schaller H. 2001. The ratio of campesterol to sitosterol that modulates growth in Arabidopsis is controlled by STEROL METHYLTRANSFERASE 2;1. The Plant journal 25, 605-615.

Schaller H. 2004. New aspects of sterol biosynthesis in growth and development of higher plants. Plant physiology and biochemistry 42, 465-476.

Schrick K, Bruno M, Khosla A, Cox PN, Marlatt SA, Roque RA, Nguyen HC, He C, Snyder MP, Singh D, Yadav G. 2014. Shared functions of plant and mammalian StAR-related lipid transfer (START) domains in modulating transcription factor activity. BMC Biology 12, 70.

Schrick K, Mayer U, Horrichs A, Kuhnt C, Bellini C, Dangl J, Schmidt J, Jurgens G. 2000. FACKEL is a sterol C-14 reductase required for organized cell division and expansion in Arabidopsis embryogenesis. Genes \& development 14, 1471-1484.

Schrick K, Mayer U, Martin G, Bellini C, Kuhnt C, Schmidt J, Jurgens G. 2002. Interactions between sterol biosynthesis genes in embryonic development of Arabidopsis. The Plant journal 31, 61-73.

Schrick K, Nguyen D, Karlowski WM, Mayer KF. 2004. START lipid/sterol-binding domains are amplified in plants and are predominantly associated with homeodomain transcription factors. Genome Biol 5, R41.

Shimada TL, Shimada T, Okazaki Y, Higashi Y, Saito K, Kuwata K, Oyama K, Kato M, Ueda H, Nakano A, Ueda T, Takano Y, Hara-Nishimura I. 2019. HIGH STEROL ESTER 1 is a key factor in plant sterol homeostasis. Nature Plants 5, 1154-1166. 
Short E, Leighton M, Imriz G, Liu D, Cope-Selby N, Hetherington F, Smertenko A, Hussey PJ, Topping JF, Lindsey K. 2018. Epidermal expression of a sterol biosynthesis gene regulates root growth by a non-cell-autonomous mechanism in Arabidopsis. Development 145.

Silvestro D, Andersen TG, Schaller H, Jensen PE. 2013. Plant sterol metabolism. Delta(7)-Sterol-C5desaturase (STE1/DWARF7), Delta(5,7)-sterol-Delta(7)-reductase (DWARF5) and Delta(24)-sterolDelta(24)-reductase (DIMINUTO/DWARF1) show multiple subcellular localizations in Arabidopsis thaliana (Heynh) L. PloS one 8, e56429.

Sonawane PD, Pollier J, Panda S, Szymanski J, Massalha H, Yona M, Unger T, Malitsky S, Arendt P, Pauwels L, Almekias-Siegl E, Rogachev I, Meir S, Cardenas PD, Masri A, Petrikov M, Schaller H, Schaffer AA, Kamble A, Giri AP, Goossens A, Aharoni A. 2016. Plant cholesterol biosynthetic pathway overlaps with phytosterol metabolism. Nature plants 3, 16205.

Song J, Sun S, Ren H, Grison M, Boutte Y, Bai W, Men S. 2019. The SMO1 Family of Sterol 4alphaMethyl Oxidases Is Essential for Auxin- and Cytokinin-Regulated Embryogenesis. Plant Physiology 181, 578-594.

Souter M, Topping J, Pullen M, Friml J, Palme K, Hackett R, Grierson D, Lindsey K. 2002. hydra Mutants of Arabidopsis are defective in sterol profiles and auxin and ethylene signaling. The Plant cell 14, 1017-1031.

Stucky DF, Arpin JC, Schrick K. 2015. Functional diversification of two UGT80 enzymes required for steryl glucoside synthesis in Arabidopsis. Journal of Experimental Botany 66, 189-201.

Suzuki M, Kamide Y, Nagata N, Seki H, Ohyama K, Kato H, Masuda K, Sato S, Kato T, Tabata S, Yoshida S, Muranaka T. 2004. Loss of function of 3-hydroxy-3-methylglutaryl coenzyme A reductase 1 (HMG1) in Arabidopsis leads to dwarfing, early senescence and male sterility, and reduced sterol levels. The Plant journal 37, 750-761.

Suzuki M, Xiang T, Ohyama K, Seki H, Saito K, Muranaka T, Hayashi H, Katsube $Y$, Kushiro T, Shibuya M, Ebizuka Y. 2006. Lanosterol synthase in dicotyledonous plants. Plant \& cell physiology 47, 565-571.

Taipale SJ, Hiltunen M, Vuorio K, Peltomaa E. 2016. Suitability of Phytosterols Alongside Fatty Acids as Chemotaxonomic Biomarkers for Phytoplankton. Frontiers Plant Science 7, 212.

Taton M, Benveniste P, Rahier A. 1987. Mechanism of Inhibition of Sterol Biosynthesis Enzymes by N-Substituted Morpholines. Pesticide Science 21, 269-280.

Thimmappa R, Geisler K, Louveau T, O'Maille P, Osbourn A. 2014. Triterpene biosynthesis in plants. Annual review of plant biology 65, 225-257.

Thoma R, Schulz-Gasch T, D'Arcy B, Benz J, Aebi J, Dehmlow H, Hennig M, Stihle M, Ruf A. 2004. Insight into steroid scaffold formation from the structure of human oxidosqualene cyclase. Nature 432, 118-122.

Topping JF, May VJ, Muskett PR, Lindsey K. 1997. Mutations in the HYDRA1 gene of Arabidopsis perturb cell shape and disrupt embryonic and seedling morphogenesis. Development 124, 44154424.

Valitova JN, Sulkarnayeva AG, Minibayeva FV. 2016. Plant Sterols: Diversity, Biosynthesis, and Physiological Functions. Biochemistry 81, 819-834.

Vranova E, Coman D, Gruissem W. 2013. Network analysis of the MVA and MEP pathways for isoprenoid synthesis. Annual Reviews of Plant Biology 64, 665-700.

Vriet C, Russinova E, Reuzeau C. 2013. From squalene to brassinolide: the steroid metabolic and signaling pathways across the plant kingdom. Molecular plant 6, 1738-1757.

Warrilow AG, Parker JE, Kelly DE, Kelly SL. 2013. Azole affinity of sterol 14alpha-demethylase (CYP51) enzymes from Candida albicans and Homo sapiens. Antimicrobial agents and chemotherapy 57, 1352-1360.

Wentzinger LF, Bach TJ, Hartmann MA. 2002. Inhibition of squalene synthase and squalene epoxidase in tobacco cells triggers an up-regulation of 3-hydroxy-3-methylglutaryl coenzyme $A$ reductase. Plant physiology 130, 334-346. 
Willemsen V, Friml J, Grebe M, van den Toorn A, Palme K, Scheres B. 2003. Cell polarity and PIN protein positioning in Arabidopsis require STEROL METHYLTRANSFERASE1 function. The Plant cell 15, 612-625.

Youn JH, Kim TW, Joo SH, Son SH, Roh J, Kim S, Kim TW, Kim SK. 2018. Function and molecular regulation of DWARF1 as a C-24 reductase in brassinosteroid biosynthesis in Arabidopsis. Journal of Experimental Botany 69, 1873-1886.

Zhang $\mathbf{X}$, Lin K, Li Y. 2020. Highlights to phytosterols accumulation and equilibrium in plants: Biosynthetic pathway and feedback regulation. Plant physiology and biochemistry https://doi.org/10.1016/j.plaphy.2020.08.021.

Zhang X, Sun S, Nie X, Boutte Y, Grison M, Li P, Kuang S, Men S. 2016. Sterol Methyl Oxidases Affect Embryo Development via Auxin-Associated Mechanisms. Plant Physiology 171, 468-482. 


\section{FIGURE LEGENDS}

Fig. 1. Key steps in squalene biosynthesis with indication of inhibitor targets

In the cytoplasm, IPP and DMAPP mainly derive from MVA, which depends on HMGR activity. Additional contributions to the cytoplasmic IPP and DMAPP pools, are phosphorylation of IP and DMAP, and IPP and DMAPP that was synthesized in the plastids via the MEP pathway. Inhibitors are indicated in red. DMAP, dimethylallyl phosphate; DMAPP, dimethylallyl pyrophosphate; FPP, farnesyl pyrophosphate; FPPS, farnesyl pyrophosphate synthase; GA-3P, glyceraldehyde 3-phosphate; GGPP, geranylgeranyl pyrophosphate; GPP, geranyl pyrophosphate; GPPS, geranyl pyrophosphate synthase; HMG, 3-Hydroxy-3-methylglutaryl; HMGR, HMG-CoA reductase; HMGS, HMG-CoA synthase; IP, isopentenyl phosphate; IPP, isopentenyl pyrophosphate; MEP, methylerythritol phosphate; MVA, mevalonate

Fig. 2: Conversion of squalene into cycloartenol and lanosterol.

SQE, squalene epoxidase; alt. SQE, alternative SQE (found in diatoms); LAS, lanosterol synthase; CAS, cycloartenol synthase, THAS, thalianol synthase. Terbinafine inhibits SQE, but not alt. SQE. RO 48-8071 inhibits the 2,3oxidosqualene cyclases LAS and CAS.

Fig. 3. Scheme of C4 and C24 metabolism in cycloartenol-derived phytosterol and cholesterol biosynthesis.

SMO1/2/3/4, sterol-4a-methyl oxidase 1/2/3/4; C4-DMC, C4-sterol demethylation complex; SMT1/2/3, C-24 sterol methyltransferase 1/2/3; SSR1/2; Sterol Side chain reductase $1 / 2$. Blue circles indicate the target sites of SMTs and SSRs at distinct positions in the sterol biosynthesis pathway. Green circles indicate the target sites of C4-DMCs. C4-(di)methylated sterol intermediates are indicated in the dashed-line box. 
Fig. 4. Parallel processing of C4-methyl sterols in phytosterol and cholesterol biosynthesis.

CPI, cycloeucalenol cycloisomerase; CVP1, cotyledon vascular pattern 1; CYP51G1, cytochrome P450 51G1; CYP710A1, cytochrome P450 710A1; DIM, DIMINUTO; DWF1/5/7, DWARF1/5/7; FK, FACKEL; HYD, HYDRA; SMO, sterol-4a-methyl oxidase. C14-R, C14 reductase, C14-DM, C14 demethylase; 8,7SI C-8,7 sterol isomerase (green-yellow background correspond to Fig.3)

Fig. 5: Schemes of the final enzymatic conversions to generate stigmasterol, campesterol and cholesterol.

DIM, DIMINUTO; DWF1/5/7, DWARF1/5/7; HYD, HYDRA; STE1, STEROL1; C5SD1/ 2; 7-DR1/ 2; SSR1; C22-SD; CYP710A1. Left: ethylesterol branch, middle, methyl-sterol branch; Right, cholesterol branch. (light and dark green-yellow backgrounds correspond to Fig. 3) 


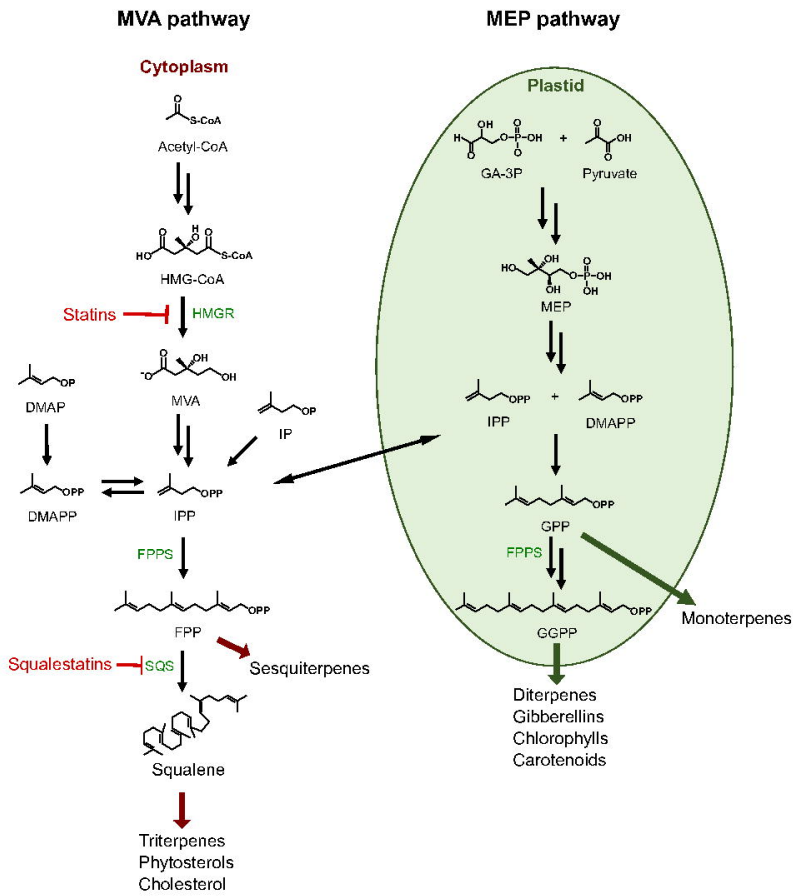

Fig. 1. Key steps in squalene biosynthesis with indication of inhibitor targets 


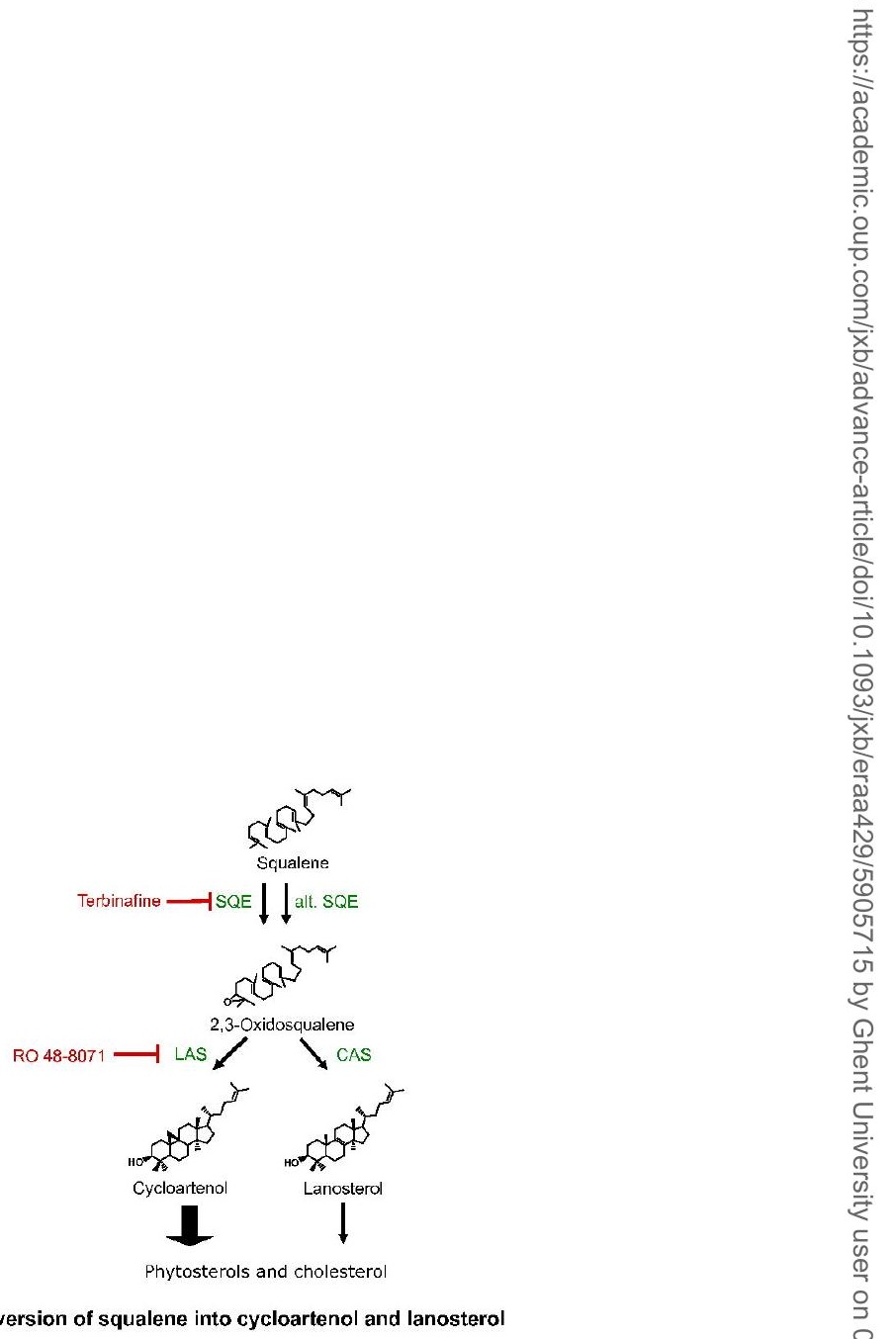




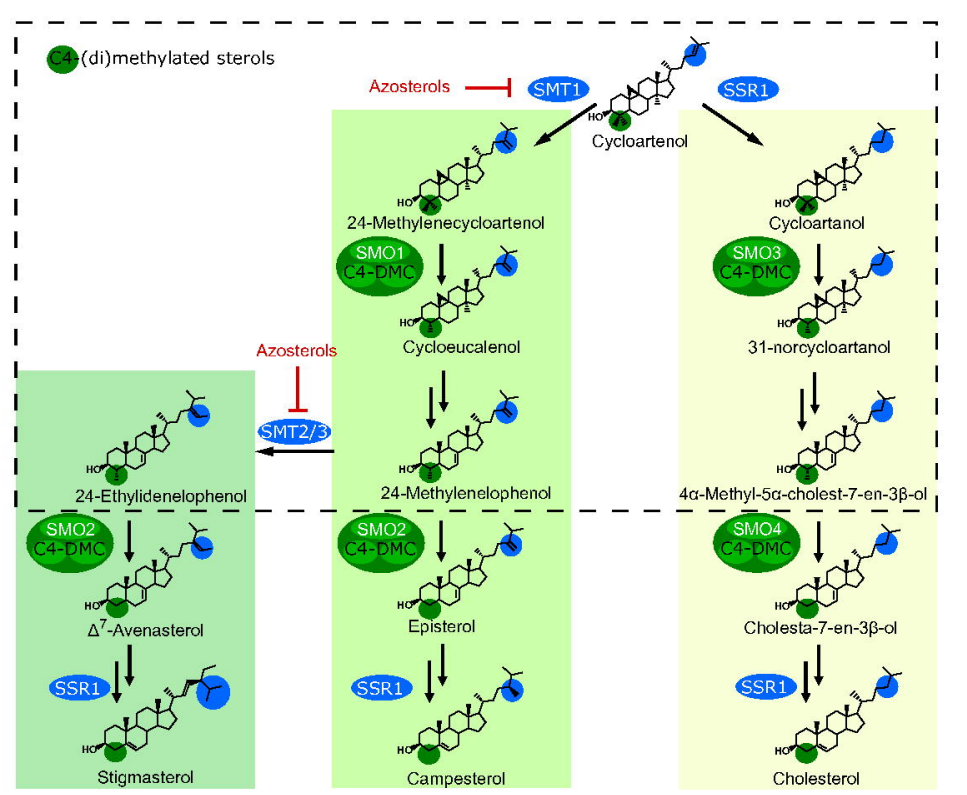

Fig. 3. Scheme of C4 and C24 metabolism in cycloartenol-derived phytosterol and cholesterol biosynthesis. 


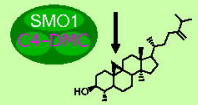

Cycloeucalenol

Morpholines LDAO

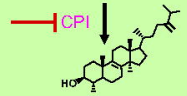

Obtusifoliol

Imidazoles Triazoles

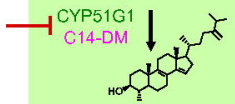

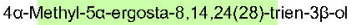

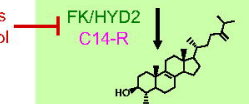

4a-Methylfecosterol

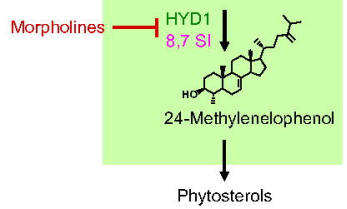

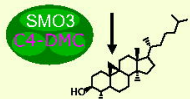

31-norcycloartanol

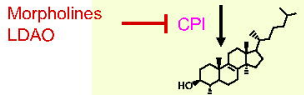

31-nor24(25)-dihydrolanosterol

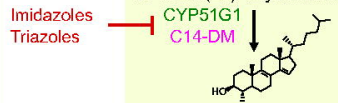

4a-Methylcholesta-8,14-dien-3 $\beta$-ol

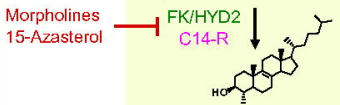

4a-Methyl-24(25)-dihydrozymosterol

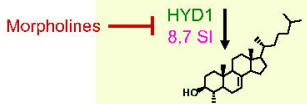

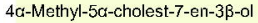

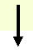

Cholesterol

Fig. 4. Parallel processing of C4 -methyl sterols in phytosterol and cholesterol biosynthesis. 

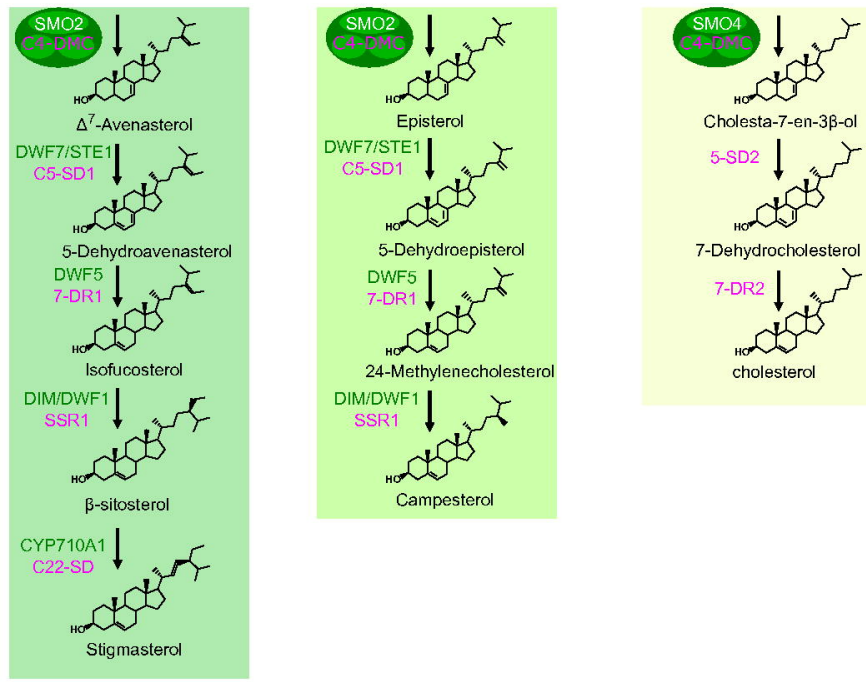

Cholesta-7-en-3ß-ol

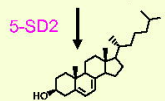

7-Dehydrocholesterol

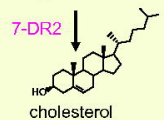

Fig. 5: Schemes of the final enzymatic conversions to generate stigmasterol, campesterol and cholesterol 